Revista Iberoamericana. Vol. LXIV, Núms. 184-185, Julio-Diciembre 1998; 441-449

\title{
CALIBÁN, ÍCONO DEL 98. A PROPÓSITO DE UN ARTÍCULO DE RUBÉN DARÍO'
}

\author{
POR \\ CARLOS JÁUREGUI \\ University of Pittsburgh
}

Para Lucas

1898 fue un año fundamental en la redefinición de la identidad latinoamericana por los intelectuales de fin de siglo. El "destino manifiesto", la aplicación heterodoxa ${ }^{2}$ de la doctrina Monroe y la tesis expansiva de Frederick Jackson Turner sobre las fronteras (1893), amenazaban no sólo a las Antillas; los intereses de los Estados Unidos (para usar la expresión de Theodore Roosevelt) crecían en Centroamérica de manera peligrosa para la soberanía de sus repúblicas y la experiencia de Cuba ese año confirmaba los peores temores de la generación modernista. México, Cuba, Puerto Rico y Filipinas eran -en el momento cumbre del imperialismo expansionista que alcanzaría a Panamá unos años más tarde - los nombres de una geografia territorial, cultural y económica, inestable. En este contexto podemos leer la fiebre verbal y el arrebato hispánico de los modernistas que, confiados en el poder de la letra, declaraban (en términos Norte/Sur) la identidad continental de la que Martí llamó "Nuestra América" y Darío la "Unión latina".

La comprensión del momento se intentó nombrando la amenaza de diversas formas: utilitarismo, materialismo, barbarie, vulgaridad democrática, y oponiéndole el Hispanismo ${ }^{3}$ en sus versiones moral, racial y lingüística. Los referentes simbólicos de esos discursos fueron idílicos lugares comunes: la invocación de valores espirituales e idealistas, la latinidad que hacía a América "hija de España", "sobrina de Francia" y "nieta de Roma", y la lengua, que permitía la conexión con el pasado español.

\footnotetext{
' Esta breve nota sobre un momento (el modernista de Darío) en el itinerario laberíntico de Calibán en Latinoamérica se inscribe en un trabajo más amplio sobre las metáforas de identidad en el continente.

${ }^{2}$ Me refiero a la aplicación a la ofensiva iniciada por el Secretario de Estado James G Blaine, bajo la administración Garfield (1881-1883) durante la cual se decidió una nueva concepción de la doctrina Monroe en el marco de la carrera imperialista entre las potencias por territorios y mercado. Blaine ocupó el mismo puesto durante la presidencia de Harrison (1889-1893) y delineó allí los objetivos comerciales (y militares) de los Estados Unidos en el Caribe y Suramérica. Para una lista de los ideólogos del imperialismo norteamericano en la década de 1890 ver Daniel Rodríguez (5-21).

${ }^{3} \mathrm{El}$ Hispanismo desde mitad del siglo XIX le hacía juego a la nostalgia imperial peninsular (Reid 123) como la idea de la latinidad al liderazgo político internacional francés (ver nota 15).
} 
El personaje Calibán de La tempestad (1611) de William Shakespeare, ícono canonizado por José Enrique Rodó en su ensayo Ariel (1900), sirvió para la composición utópica del imaginario histórico en un presente conflictivo e inasible, y para impugnar el materialismo vulgar de los nuevos tiempos. ${ }^{4}$ La apropiación latinoamericana de los personajes del drama (Calibán, Ariel, Miranda, Próspero) es, sin embargo, generacional, modernista; antes de que la propusiera Rodó estaba ya en el imaginario de la época. Esta breve nota quiere introducir uno de los documentos que da cuenta de ello, un artículo de Rubén Darío que quedó más o menos sepultado entre su prosa periodística y que ha sido descuidado por la crítica: " "El triunfo de Calibán" aparecido en El Tiempo de Buenos Aires (20 de mayo de 1898) y en El Cojo Ilustrado de Caracas (1 de octubre de 1898).

Dos años antes que Rodó lo hiciera, Darío - un Darío de 1898, visto tradicionalmente como el escapista y esteta de la "torre de marfil"- - usaba con una retórica frontal la oposición Ariel/Calibán en su condena a los Estados Unidos, a propósito de la guerra de Cuba. ${ }^{6}$ Rodó, empero, establece una genealogía francesa (Ernest Renan) en la que no se halla Darío, ${ }^{7}$ ni tampoco el franco-argentino Paul Groussac, director de la Biblioteca Nacional, de quien - se dice- él y Darío habrían tomado la idea. Algunas exposiciones, en efecto, tienden a darle ese papel central a Groussac, lo cual es menester aclarar. El 2 de mayo de 1898, en el teatro La Victoria, en un evento patrocinado por el Club español de Buenos Aires a raíz de la guerra entre los Estados Unidos y España, Groussac se había referido a la agresión "yankee", y al cuerpo monstruoso (calibanesco) de los Estados Unidos. En medio de sus reflexiones sobre las bondades de la Conquista, las excelencias de la literatura española, y la observación sobre la inmadurez de Cuba para la independencia (!), decía:

en el umbral del siglo XX ella [la civilización latina] mira erguirse un enemigo más formidable y temible que las hordas bárbaras [...] desde la guerra de Secesión y la brutal invasión del Oeste, se ha desprendido libremente el espíritu yankee del cuerpo informe y 'calibanesco'; [...] Esta civilización, embrionaria e incompleta en su deformidad, quiere sustituir la razón con la fuerza[...] No tiene alma, mejor dicho: sólo posee esa alma apetitiva que en el sistema de Platón es fuente de las pasiones groseras y de los instintos físicos (énfasis mío, Viaje intelectual 100, 101).

Antes de la publicación de Ariel y casi simultáneamente con la referencia citada de Groussac, Darío propuso en "El triunfo de Calibán" el "personaje metáfora" que le

\footnotetext{
${ }^{4}$ Para Fernández-Retamar, Calibán funciona como un "concepto-metáfora" (Spivak) o "personaje conceptual” (Deleuze y Guattari), (“Adios a Calibán" 79).

${ }^{5}$ Hacen menciones y referencias breves al texto: Arciniegas (315), Arellano ("Rubén Darío" 106; Los raros: una lectura 83), Allen (387-89), Balseiro (120-21), Castells (165), Castro-Morales (en Rodó 152), Reid (195), Rodríguez-Monegal (80), Vaughan (147), etc. De estos trabajos el de Balseiro (1967) es el más extenso en su comentario.

${ }^{6}$ El 11 de abril de 1898 el presidente William McKinley solicitó autorización al Congreso (obtenida días después) para intervenir en Cuba "para parar la guerra" entre España y los independentistas cubanos que la tenían prácticamente ganada.

${ }^{7}$ Así mismo ocurrió en el ensayo de Fernández-Retamar, aunque una nota a pie de página aparecida en la edición de 1995 corrige la omisión (33).
} 
permitiría articular ese alegato desgarrado en favor de una idílica cultura hispánica fundada en valores espirituales, contra el modelo igualitario y capitalista de los Estados Unidos. ${ }^{8}$ Cuatro años antes de los eventos del teatro La Victoria y del artículo que se publica, Darío ya había adelantado a Calibán en su semblanza de Edgar Allan Poe publicada en la Revista Nacional' en enero de 1894, que incluyera luego en Los raros (1896). Al comienzo de ésta hace un recuento de su viaje a la ciudad de New York (1893) que recuerda bajo el acaloramiento y disgusto que le causaba "la sanguínea, la ciclópea, la monstruosa ... capital del cheque" $(14,15)$ y anticipa al Calibán de su artículo de 1898 :

"esos cíclopes ..." dice Groussac; "esos feroces calibanes ..." escribe Peladan. ¿Tuvo razón
el raro Sãr al llamar así a estos hombres de la América del Norte? Calibán reina en la isla
de Manhattan, en San Francisco, en Boston, en Washington, en todo el país. Ha conseguido
establecer el imperio de la materia desde su estado misterioso con Edison, hasta la
apoteosis del puerco, ${ }^{10}$ en esa abrumadora ciudad de Chicago. Calibán se satura de whisky,
como en el drama de Shakespeare de vino; se desarrolla y crece; y sin ser esclavo de ningún
Próspero, ni martirizado por ningún genio del aire, engorda y se multiplica; su nombre es
Legión. Por voluntad de Dios suele brotar de entre esos poderosos monstruos, algún ser
de superior naturaleza, que tiende las alas a la eterna Miranda de lo ideal. Entonces Calibán
mueve contra él a Sícorax, y se le destierra o se le mata. Esto vio el mundo con Edgar Allan
Poe, el cisne desdichado que mejor ha conocido el ensueño y la muerte [...] Poe, como un
Ariel hecho hombre, diríase que ha pasado su vida bajo el flotante influjo de un extraño
misterio. Nacido en un país de vida práctica y material, la influencia del medio obra en él
al contrario $(16,17,19)$.

David Allen (386) supone que "Chicago: la ciudad y la exposición" de Del Plata al Niágara (1897) de Groussac habría influido en la nota sobre Poe de Darío. Según él, ese capítulo fue publicado en 1883 en un periódico - que no cita-en Buenos Aires. Aunque el texto está fechado en octubre de 1883 y la hipótesis de Allen es interesante y muy probable, la noticia de publicación que tenemos es la de la edición de 1897 (Canter 12). Aún aceptando que el capítulo de Groussac hubiera sido publicado antes, la mención que allí aparece está referida a la belleza "calibanesca" de Chicago (345), lo que de cualquier manera no tiene el alcance de la oposición binaria Ariel/Calibán; además ... ¿No ignoraríamos que

\footnotetext{
${ }^{8}$ Recurrirá de nuevo a este motivo, aunque sin la centralidad del ensayo del 98, en "Los anglosajones" de Peregrinaciones: "Entre esos millones de Calibanes nacen los más maravillosos Arieles" (Balseiro 126). El calibanismo es una clave de lectura de una serie de artículos y poemas que incluyen entre otros textos: "D.Q." (1899), "La invasión de los bárbaros del norte" (1901), "Invasión anglosajona: Centroamérica yanqui" (1902), “A Roosevelt" (1905) y "Salutación al Aguila" (1907).

${ }^{9}$ Arellano refiere esta publicación temprana (Los raros: una lectura 28 ). También hay una mención de Calibán en la semblanza "Augusto de Armas" de Los raros, como lo señaló Pedro Lastra (en Schulman 205); en ese escrito Darío dice de Stuart Merrill que: "como Poe, nación en ese país que Peladan tiene razón en llamar de Calibanes". Este texto, publicado en La Nación el 4 de septiembre de 1893 (Arellano, Los raros: una lectura integral 26-27), constituye una referencia, si bien breve, temprana y significativa, especialmente por la fuente mencionada, vale decir: Peladan.

${ }^{10}$ Esta alusión coincide con la de Groussac en Del Plata al Niágara (1897) en donde llama a Chicago Porcópolis (298).
} 
Darío en Los raros declara a Peladan como su fuente cuando dice: “"esos feroces calibanes [...]' escribe Peladan"?

El Sãr, Joséphin Peladan (1858-1918), a quien Darío "leía con particular devoción" (Arciniegas 315), fue un novelista y ocultista francés en la corriente angelista (opuesta al satanismo) y fundador de la orden Rose-Croix (1892), que gozaba de gran prestigio entonces (Pincus 2-9). Peladan había profetizado el triunfo del materialismo (Arellano, Los raros: una lectura 85) y de allí la conveniencia y pertinencia de la adopción de ese ícono que coadyuvaba la oposición al positivismo científico y al materialismo. La declaración de Darío sobre su fuente es clara y le queda a la crítica el rastreo de ese Calibán, hijo putativo de América, del espiritismo francés y de las ciencias ocultas a las que fue propenso el Modernismo. ${ }^{11}$

Darío, se dijo, poco le debería a la mención pasajera de Groussac sobre Chicago, aún en el caso de haber sido ésta publicada antes de 1894. Me inclino a pensar que hubo cierta simultaneidad en el uso de una metáfora afrancesada que estaba en el ambiente. Ahora bien, si se acepta como probable la deuda de Darío con Groussac, no sucede lo mismo con la supuesta influencia de Renan; no tenemos indicios que permitan una lectura extensiva de las fuentes de Ariel como si fueran las mismas de "El triunfo de Calibán".

"El triunfo de Calibán" fue reescrito a partir del texto sobre Poe. Rodó, por su parte, no obstante que conoció Los raros (Balseiro 121) y muy probablemente había leído "El triunfo de Calibán" antes de escribir su Ariel, no menciona a Darío. Renan le sirve de autoridad "mejor" que el nicaragüense. Por otra parte aunque ambos ensayos tienen como presupuesto "los valores de la latinidad", el de Rodó difiere por su tono reposado y porque en él la oposición Ariel/Calibán es menos explícita. Ariel "presupone la amenaza de Calibán" (Ramos 217) pero no la hace manifiesta; el genio del aire se opone casi tácitamente a un escasamente mencionado Calibán.

El texto sobre Poe en Los raros precede y contiene la mayoría de las asociaciones del alegato del 98: el yankee es el monstruo Calibán, un ser moralmente inferior que sucumbe al vicio de la bebida, ${ }^{12}$ y que reemplaza la razón con la fuerza, en contraste con Ariel que representa las alturas del espíritu; la bestia encarna el materialismo, una forma satánica del mal ("su nombre es Legión"13) vinculada al modelo norteamericano cuyas ciudades son emblemáticas de la "civilizacion bárbara" (oxímoron que conjuga los extremos de la proposición de Sarmiento); Miranda aparece como un eterno femenino virginal/maternal que extiende sus brazos al idealismo" "latino"; y por último, las excepciones confirman la regla: Poe y Lanier (quien "se salva por la gota latina que brilla en su nombre") se baten contra - y existen a pesar de - un medio corrupto que ha quebrado la aristocracia del espíritu.

"Sobre esta relación, la credulidad de la época, y en especial la de Darío, ver "Espiritismo y modernismo" (Gullón en Schulman 86-122).

${ }^{12}$ A Calibán sólo lo doblega el vino que Esteban y Trínculo usan para domesticarlo (2024-25) y bajo cuya influencia los cree dioses convirtiéndose en "¡el más crédulo de los monstruos!" (2026) dispuesto a lamer los zapatos de Esteban (2029).

${ }^{13}$ (Marcos 5:9).

${ }^{14}$ En el artículo del 98 dice: "Miranda preferirá siempre a Ariel; Miranda es la gracia del espíritu". 
El discurso elitista de la crisis finisecular modernista no pensó la época fuera del antipragmático y aristocrático manifiesto de la latinidad. Esta visión del imperialismo "como una contradicción a la tradición hispánica, y un ataque a los fueros de la intelligentsia elevada por encima de la masa" (Moraña, Literatura y cultura 67), es un síntoma del desencuentro de estos intelectuales con la modernidad (parafraseando una expresión de Julio Ramos) y una marca de los límites de su lectura de la cultura y la historia. Al nombrar su causa de identidad como la de la raza latina, acudían a una idea racista, de factura francesa y paradójicamente diseñada en el proceso de constitución del botín americano ${ }^{15}$ que se disputaban potencias como Inglaterra, Francia y Los Estados Unidos, esos "gigantes que llevan siete leguas en las botas" — como decía Martí en 1891 - que libraban una "pelea de cometas en el cielo" y que iban "por el aire dormido engullendo mundos" ("Nuestra América", Oc VI, 15). A esta contradicción debe sumarse, en el caso de Darío, la inconstancia de la beligerancia espiritual "latina" contra el "imperio de la materia" y la "apoteosis del puerco" yankee; el latinismo que en 1898 concluye: “¡Miranda preferirá siempre a Ariel; Miranda es la gracia del espíritu; y todas las montañas de piedras, de hierros, de oros y de tocinos, no bastarán para que mi alma latina se prostituya a Calibán!" ("El triunfo" 455), ${ }^{16}$ no resiste la lectura de los versos de "Salutación al águila" (1907): "Tráenos los secretos de las labores del Norte, / y que los hijos nuestros dejen de ser los rétores latinos / y aprendan de los yanquis la constancia, el vigor, el carácter" (Poesías Completas II, 707709).

Tres paradojas adicionales pueden ilustrar los límites del discurso calibánico del 98:

1. En "El triunfo de Calibán" Darío insiste repetida y pródigamente en imágenes de consumición:

comedores de carne cruda [...] Comen, comen [...] la asechanza de la boca del bárbaro [...] el peligro que entrañan esas mandíbulas de boa todavía abiertas tras la tragada de Tejas; la codicia del anglosajón, el apetito yankee [...] ¿Qué diría hoy el cubano [Martí] al ver que so color de ayuda para la ansiada Perla, el monstruo se la traga con ostra y todo? [...] Mas he ahí que del norte, parten [...] bocas absorbentes [...] a la vista está la gula del Norte, etc. $(451,452,453,454)$.

En "Invasión anglosajona: Centroamérica yanqui" (1902) denunciará de nuevo el apetito de los Estados Unidos justo antes de la intervención en Panamá y temiéndola en Nicaragua:

${ }^{15}$ El Panlatinismo en la segunda mitad del siglo estaba ligado a los intereses de la política exterior francesa que quería colocarse al frente de los países latinos y hacer contrapeso a las "naciones anglosajonas". Desde la década de 1850 esa idea tuvo defensores como Michel Chevalier (1806-1879) y Ernest Renan (1823-1892) que habían impulsado un modelo geoideológico que legitimaba la expansión económica de Francia y su patronazgo cultural. En Suramérica la idea resurge a partir de la década 1880 y es usada por los modernistas contra los Estados Unidos (Phelan 5-21).

${ }^{16}$ Todas las citas y referencias de páginas del artículo de Darío "El triunfo de Calibán" se realizan de acuerdo a la edición del mismo en este volumen. 
Un ministro de la República de Nicaragua - el señor Gómez - decía al célebre escritor colombiano Vargas Vila: "Que los americanos nos han de comer, es un hecho. No nos queda más que escoger la salsa con que hemos de ser comidos” (Escritos dispersos 142).

Sin embargo Darío, que tenía frente a sí esta imagen del imperio voraz, no relacionó a Calibán con el término caníbal, más acorde con el campo léxico de su caracterización de los Estados Unidos. El anagrama, que suponemos obvio, no lo era tanto para Darío, o no del todo.

2. La resistencia humanista a la consolidación del poder hegemónico norteamericano y al imperialismo no encuentra un ícono en Calibán, como sucederá posteriormente con la avanzada contracolonial en el Caribe (Lamming, Cesaire, Fernández-Retamar). Darío y Rodó no se reconocen en el monstruo colonizado que maldice al usurpador, sino en Ariel o en Próspero. ${ }^{17}$

Calibán maldice a Próspero en un gesto de rebeldía maniatado por el poder del invasor. Darío, en 1898, sabe o se declara sujeto de un heroísmo de la inutilidad, pero no reconoce en sus palabras el drama calibánico:

Pero hay quienes me digan: “¿No ve usted que son más fuertes? ¿No sabe usted que por ley fatal hemos de perecer tragados o aplastados por el coloso? No reconoce usted su superioridad? Sí, ¿cómo no voy a ver el monte que forma el lomo del mamut? Pero ante Darwin y Spencer no voy a poner la cabeza sobre la piedra para que me aplaste la gran bestia [...] no he de sacrificarme por mi propia voluntad bajo sus patas, y si me logra atrapar, al menos mi lengua ha de concluir de dar su maldición última, con el último aliento de vida (455).

3. De la pluma de Martí obtuvo Darío el material de una lectura intensa de los Estados Unidos (el lector de "El triunfo de Calibán" notará cierta intertextualidad, por ejemplo en los juicios severos a Blaine y a Gould), pero su defensa de España en las condiciones de ese momento era un alegato contra Cuba y contra la herencia política de Martí, pese a los golpes de pecho al final del texto. ${ }^{18}$

Darío dirige su "panfleto cultural"19 contra los Estados Unidos, no contra España ${ }^{20} \mathrm{y}$, en este sentido, la identificación con Ariel, el sirviente del Próspero, es coherente con el papel instrumental del intelectual defensor de los intereses peninsulares.

\footnotetext{
${ }^{17}$ Darío probablemente no estaba al tanto, o no le interesaba, la lectura romántica de La tempestad hecha por William Hazlitt (1818) — a raíz de una discusión con Coleridge sobre la imputación que éste hiciera a los Jacobinos de ser usurpadores, bárbaros y calibanes - en que cuestionó el derecho del invasor "civilizado" y afirmó el derecho a resistir que asistía a Calibán, "the legitimate sovereign of the isle", contra "Prospero and the rest of the usurpers" (Oc III, 207).

${ }^{18}$ Esas simpatías pueden rastrearse en las celebraciones del "Descubrimiento" en las que participó Darío en 1892.

${ }^{19}$ Jameson usa esta expresión al hablar del "Calibán" de Fernández-Retamar (6).

${ }^{20}$ Darío por momentos está respecto a Fernández-Retamar más cerca de lo que pudiera pensarse. Tiene una diferencia de tropos pero el sentido de su alegato es direccionalmente paralelo: el reclamo de una identidad y unidad latinoamericana, opuesta a la intervención y avance de los Estados Unidos.
} 
Arturo Andrés Roig, hablando de Martí, Hostos, Darío y Rodó, dice que el discurso del 98 americano no es

expresado en lo que en la Península se llamó "literatura del desastre" o de la "decadencia española", expresión de la frustración histórica, de sentimientos injustificados de desaliento y derrota. ¿Cómo iban a lamentar los caribeños el fin de un imperio? Lo que sí habían de lamentar y lamentamos todavía, fue el remplazo de aquel por otro $(135,136)$.

Por lo que respecta a "El triunfo de Calibán" no se puede aceptar la tesis de Roig; ese discurso antiimperialista se prestaba a la política exterior española; ${ }^{21}$ la simpatía de Darío por la causa martiana es apenas sentimental: "Y yo que he sido partidario de Cuba libre, siquier fuese por acompañar en su sueño a tanto soñador y en su heroísmo a tanto mártir, soy amigo de España en el instante en que la miro agredida por un enemigo brutal" (455). Darío lamenta el surgimiento del nuevo imperio, es cierto, pero no deja de llorar el fin del anterior.

Estos límites de la metáfora —el que no relacione Calibán/Caníbal, que no asocie Calibán/América Latina, y/o que no extienda el escenario conceptual de La tempestad a España-pueden tener relación causal con las pobres herramientas del humanismo burgués para entender su tiempo allende su espiritualismo antipragmático. Lo que se ha indicado respecto de Ariel, es decir, que no se detuvo en "las causas político-económicas del fenómeno imperialista" sino que se quedó en la resistencia axiológica programática (Moraña en Iñigo 660), puede bien hacerse extensivo a "El triunfo de Calibán".

La posición problemática de esta generación tiene su nudo en la pérdida de autoridad de su quehacer letrado y en el correspondiente intento por legitimar la literatura en la medida de su resistencia a los flujos de la modernización (Ramos 10), al tiempo que - para defender a una potencia decadente contra una emergente-, se permitía retozos eurocéntricos ${ }^{22} \operatorname{como}^{-}$ la construcción de un discurso de identidad con fuentes en Shakespeare, en los ideólogos del imperialismo francés, o, en el mejor de los casos, en sus espiritistas.

Por ello Groussac, sin rubor, habla de la inmadurez de Cuba para la independencia y Darío trae a su monólogo a una España vetusta y no a la que libró una guerra contra los cubanos y que, de alguna manera, con su insistencia en conservar las colonias, sirvió a Cuba en bandeja a la intervención de los Estados Unidos: "la España que yo defiendo - decíase llama Hidalguía, Ideal, Nobleza; se llama Cervantes, Quevedo, Góngora, Gracián, Velázquez; se llama el Cid, Loyola, Isabel; se llama la I Iija de Roma, la Hermana de Francia, la Madre de América" ("El triunfo" 455). Obviaba la España que hizo de la población civil

${ }^{21}$ También puede pensarse en otros intereses como los del proyecto liberal argentino que tenía la pretensión de erigir una potencia en el sur del continente: "Saenz Peña, el argentino cuya voz en el Congreso panamericano [...] demostró en su propia casa al piel roja que hay quienes velan en nuestras repúblicas por la asechanza de la boca del bárbaro" ("El triunfo" 452). Esta lógica del contrapeso se repite en "A Roosevelt": "Apenas brilla, alzándose, el argentino sol" (Poesias Completas II, 639641).

${ }^{22}$ Martí había denunciado este pensar en francés o en inglés o en el caso del ensayo que nos ocupa, pensar a Cuba desde Madrid ("Nuestra América", Oc VI, 15-23). 
de la isla un objetivo militar en la campaña de tierra arrasada del general español Valeriano Weyler en 1896.

"El triunfo de Calibán", en conclusión, tiene un valor representativo de los debates de la época y del imaginario del 98, de los alcances y límites del discurso frente a la modernidad, el imperialismo y la identidad continental, e indica el rumbo de la imaginación histórica generacional del fin de siglo. Cuando Rodó escribe su ensayo interpelando en su dedicatoria a "la juventud de América" parece mirar al futuro; en realidad cerraba, bajo el ropaje de propuesta de un deber ser, una época en agonía. Detrás de la grandilocuencia de ese texto, y de la vehemencia enconada del de Darío, estaba la misma frustración e impotencia, la de una generación que hizo un discurso utópico en las puertas de su Apocalipsis.

\section{Bibliografía}

Arciniegas, Germán. "Darío o la doble perspectiva en el destino de América". La torre 55/ 56 (1967): 311-321.

Arellano, Jorge Eduardo. Los raros: una lectura integral. Managua: Instituto Nicaragüense de Cultura, 1996.

"Rubén Darío antiimperialista". Casa de las Américas 133 (1982): 104-108.

Allen, David. "Rubén Darío frente a la creciente influencia de los Estados Unidos". Revista Iberoamericana 64 (1967): 387-393.

Balseiro, José Agustín. Seis estudios sobre Rubén Dario. Madrid: Gredos, 1967.

Canter, Juan. Contribución a la bibliografia de Paul Groussac. Buenos Aires: El ateneo, 1930.

Castells, Ricardo. "Fernández Retamar's The Tempest in a Cafetera: From Ariel to Mariel”. Cuban Studies 25 (1995): 165-182.

Cesaire, Aimé. A Tempest. Richarch Miller, trad. New York: UBU, 1992.

Darío, Rubén. Los raros. Barcelona y Buenos Aires: Maucci, 1905. Poesías Completas. Madrid: Aguilar, 1967.

Escritos dispersos de Rubén Darío. La Plata: Universidad Nacional de La Plata, 1968.

"El triunfo de Calibán". El Cojo Ilustrado de Caracas (1 de octubre de 1898): 676;

E.K. Mampes, Escritos inéditos de Rubén Dario. New York: Instituto de las Españas, (1938): 160-162; Ricardo Gullón, El Modernismo visto por los modernistas (1980): 404-409.

Fernández-Retamar, Roberto. "Calibán”. Casa de las Américas 68 (1971): 124-151; Para un perfil definitivo del hombre. Habana: Letras cubanas, 1981; Calibán - Contra la leyenda negra. Lleida: Universitat de Lleida, 1995.

“Adios a Calibán". Milenio 3 (1995): 79-84.

Groussac, Paul. Viaje intelectual: impresiones de la naturaleza y el arte. Primera serie. Madrid: Victoriano Suárez, 1904. Del Plata al Niágara. Buenos Aires: Jesús Menendez, 1925.

Halzitt, William. Characters of Shakespear's Plays. Londres: C. H. Reynell, 1817. "Mr. Coleridge's Lectures". The Complete Works of William Hazlitt 3. Londres y Toronto: Dent and Sons, 1930-34. 206-210. 
Jameson, Frederic. "Prefacio a Calibán". Nuevo texto crítico 3/5 (1990): 3-8.

Lamming, George. The Pleasures of Exile. Ann Arbor: University of Michigan Press, 1992.

Martí, José. Obras completas VI, IX-XII. La Habana: Editorial nacional, 1963-65.

Moraña, Mabel. Literatura y cultura nacional en Hispanoamérica: 1910-1940. Minneapolis: Institute for the Study of the Ideologies and Literatures, 1984.

"Jose Enrique Rodó". Historia de la literatura hispanoamericana II, del neoclasicismo al modernismo. Luis Iñigo Madrigal. Madrid: Cátedra, 1993.

Phelan, John L. El origen de la idea de América. México: UNAM, 1979.

Pincus-Witten, Robert. Occult symbolism in France: Joséphin Peladan and the Salons de la Rose-Croix. New York: Garland, 1976.

Ramos, Julio. Desencuentros de la modernidad en América Latina: literatura y política en el siglo XIX. México: Fondo de Cultura Económica, 1989.

Reid, John. Spanish American Images of the United States 1790-1960. Gainesville: University of Florida Press, 1977.

Renan, Ernest. Caliban: A Philosophical Drama Continuing "The Tempest" of William Shakespeare. New York: AMS Press, 1971.

Rodó, José Enrique. Ariel. Madrid: Anaya y Mario Muchnik, 1995.

Rodríguez-Monegal, Emir. "The Metamorphoses of Caliban". Diacritics 7/3 (1977): 7883.

Rodríguez, Daniel. Los intelectuales del imperialismo norteamericano de la década de 1890. México: UNAM, 1979.

Roig, Arturo-Andrés. “Calibán y el 98”. Latin American Literary Review 50 (1997): 133137.

Schulman, Ivan. Nuevos asedios al Modernismo. Madrid: Taurus, 1987.

Shakespeare, William. "La tempestad". Obras completas. Madrid: Aguilar, 1960.

Vaughan, Alden y Virginia Mason. Shakespeare 's Caliban: A Cultural History. Cambridge: Cambridge University Press, 1996. 
